\title{
SITUACIÓN JURÍDICA DEL MENOR EN EL ÁMBITO DE LAS COFRADÍAS Y HERMANDADES. ESPECIAL REFERENCIA AL DERECHO DE ASOCIACIÓN
}

\author{
María Soledad de la Fuente Núñez de Castro. \\ Profesora Titular de Derecho Civil. \\ Departamento de Derecho Civil, Derecho Eclesiástico del Estado \\ y Derecho Romano. Facultad de Derecho. \\ Universidad de Málaga. \\ E-mail: msfuente@uma.es
}

\begin{abstract}
RESUMEN: La capacidad natural del menor acorde a su desarrollo volitivo e intelectivo es una cuestión sobre la que no cabe controversia alguna. Esta capacidad natural, llegada a una determinada edad biológica, le permite el ejercicio por sí solo de ciertos derechos. El derecho de asociación es uno de ellos como derecho fundamental que es, de carácter personalísimo, legitimándolo para la creación de asociaciones infantiles, juveniles y aquellas otras que si bien de carácter general, la normativa lo habilita para ello. Una asociación pública de fieles es la consecuencia del ejercicio de este derecho de asociación, si bien mediatizado por la jerarquía eclesiástica, bajo los postulados del Derecho Canónico. En esta labor reguladora parecería que del Derecho Civil queda relegado. Sin embargo, el estudio comparado de ambas regulaciones, sus convergencias y diferencias, constituye una pieza fundamental para equilibrar en estos órdenes jurídicos la relación entre ambos. No obstante, la intervención de un menor en una hermandad no se limita a su posible función creadora de la misma. Su pertenencia a una ya existente le atribuye derechos y deberes con consecuencias en el ámbito jurídico.
\end{abstract}

Palabras claves: menor, capacidad natural, derecho de asociación, hermandad.

ABSTRACT: The child's natural capacity according to his volitional and intellectual development is a question about which there is no controversy. This natural capacity, reached a certain biological age, allows you to exercise certain rights on your own. The right of association is one of them as a fundamental right that is, of a very personal nature, legitimizing it for the creation of children's, youth and other associations that, although of a general nature, the regulations enable it to do so. A public association of the faithful is the consequence of the exercise of this right of association, although mediated by the ecclesiastical hierarchy, under the postulates of Canon Law. In this regulatory work it would seem that Civil Law is relegated. However, the comparative study of both regulations, their convergences and 
differences, constitutes a fundamental piece to balance in these legal orders the relationship between the two. However, the intervention of a minor in a brotherhood is not limited to its possible creative role. Its membership in an existing one attributes rights and duties with consequences in the legal field.

Keywords: minor, natural ability, right of association, brotherhood.

\begin{abstract}
SUMARIO: I. INTROdUCCIÓN. II. LA CAPACIDAD NATURAL DEL MENOR. III. EL DERECHO DE ASOCIACIÓN DEL MENOR DE EDAD. 3.1. El ejercicio del derecho de asociación por el menor en el ámbito civil. 3.2. El derecho de asociación del menor en el ámbito del derecho canónico. Especial referencia a la participación del menor en cofradías y hermandades. 3.2.1 El derecho de asociación del menor de edad en el ámbito propio del derecho canónico. 3.2.2. Especial referencia a la participación del menor de edad en cofradias y hermandades: su inscripción y participación en la estación de penitencia. IV. APLICACIÓN DEL REGLAMENTO EUROPEO 2016/679 DE PROTECCIÓN DE DATOS Y DE LA LEY ORGÁNICA 3/2018, DE 6 DICIEMBRE, DE PROTECCIÓN DE DATOS PERSONALES Y GARANTÍAS DE LOS DERECHOS DIGITALES EN LAS HERMANDADES Y COFRADÍAS: SU REPERCUSIÓN EN LOS MENORES DE EDAD. V. RECAPITULACIÓN. VI. BIBLIOGRAFÍA.
\end{abstract}

\title{
I. INTRODUCCIÓN
}

En un momento en el que la capacidad natural del menor no puede ser cuestionada conforme a un desarrollo intelectivo y volitivo parejo a su edad cronológica, son numerosos los escenarios donde se pueden plantear su intervención autónoma, independientemente de la asistencia o incluso de la representación de sus padres o tutores.

El ámbito de las cofradías y hermandades es uno de ellos, mucho más cuando la pertenencia a una de éstas suele ser consecuencia de una tradición familiar, que incluso ha podido promover en estos menores con capacidad natural la promoción de una asociación pública de fieles.

La repercusión jurídica de este planteamiento constituye el eje en torno al cual gira la investigación que a continuación se expone.

Es por ello, que por un lado se intenta dar respuesta al deseo que puede surgir entre menores de edad con capacidad natural, generalmente en torno a los 14 años cumplidos, en su intención de erigir una asociación pública de fieles. Esta circunstancia nos avoca inevitablemente al estudio del ejercicio del derecho de asociación que ostenta el sujeto de derecho. Ahora bien, la fundación de una cofradía o hermandad es competencia del Derecho Canónico a través de la normativa propia de cada diócesis española que imita un modelo a seguir elaborado por la autoridad eclesiástica competente. El desarrollo del derecho de asociación en el ámbito civil por la normativa orgánica pertinente queda relegado. Sin embargo, considero fundamental un estudio comparado del mismo derecho desde vertientes jurídicas distintas, delimitando de esta forma aquello en lo que convergen y en lo que discrepan en un intento en que, bajo determinadas circunstancias, puedan complementarse.

La actuación de un menor en el seno de una cofradía o hermandad ya constituida y a la que pertenece bajo la autorización de sus padres o tutores conforma otro aspecto a tratar. Esa pertenencia se hace patente en el ejercicio de los derechos y el cumplimiento 
de los deberes inherentes a su condición de hermano con repercusión en la esfera jurídica del menor. A ello también dedico parte de este estudio.

\section{LA CAPACIDAD NATURAL DEL MENOR}

Jurídicamente la minoría de edad es un estado civil que comprende temporalmente el periodo de tiempo que trascurre entre el nacimiento de una persona física, bajo las condiciones establecidas en los artículos 29 y 30 del Código Civil -CC- hasta el momento en el que cumple 18 años.

Cuando el sujeto nace con las condiciones establecidas en los artículos 29 y 30 del $\mathrm{CC}$ adquiere la capacidad jurídica o personalidad, es decir, es sujeto para el Derecho y de derecho, pudiendo ser titular de derechos y obligaciones.

A este respecto el art. 29 del CC establece que «el nacimiento determina la personalidad (...)», si bien el art. 30 especifica el momento en el que se adquiere la personalidad que no es otro que «el momento del nacimiento con vida, una vez producido el entero desprendimiento del seno materno»; es decir, una persona es sujeto de derechos desde el mismo instante del nacimiento siempre y cuando tenga vida independiente de su madre.

La capacidad de obrar, es decir, la posibilidad de que el sujeto ejercite por sí mismo los derechos y deberes de los que es titular desde su nacimiento o que ha podido ir adquiriendo durante los años de su minoría de edad, la alcanza el individuo cumplidos los 18 años, mientras tanto habrá de estar representado por sus representantes legales: padres $\mathrm{y}$ tutores.

Esta afirmación nos llevaría a identificar el estado civil de la minoría de edad con la situación del incapacitado por sentencia judicial firme ${ }^{1}$, vetando al menor, independientemente de la edad cronológica que tenga y de su madurez - 8 meses, 3 años, 8 años, 12 años o 17 años-, el poder actuar por sí mismo en el tráfico jurídico y económico obviando su capacidad de discernimiento, es decir, la capacidad de entender y querer la trascendencia jurídica del acto que lleva a cabo ${ }^{2}$.

Sin embargo, la capacidad general de las personas es variable o flexible en función del grado de desarrollo intelectivo y volitivo que socialmente corresponde a cada edad y al estado físico y psíquico en que se encuentre cada sujeto. A diferencia de lo que ocurre en el Código Civil catalán -art. 211.3 CCcat-, nuestro Derecho Común no fundamenta la capacidad de obrar de la persona en su capacidad natural. Por lo tanto, en Cataluña, la capacidad de obrar y con ello la posibilidad jurídica de hacer frente a los propios asuntos a través de una actuación singular e individualizada, se revela como cauce ordinario del

1 En una correcta terminología a identificarlo con un sujeto al que se le ha modificado judicialmente su capacidad de obrar.

2 En este sentido, confr. DEGANO, «La ficción jurídica de la Minoridad y la Subjetividad Infantil, Fundamentos en Humanidades, 2006, pp. 30 y ss.; MARTÍN BRICEÑO, «La capacidad contractual del menor no emancipado tras la Ley 26/2015, de 28 de julio, de modificación del sistema de protección a la infancia y a la adolescencia», Actualidad Civil, n³, 2017, pp. 7 y ss; MONTEJO RIVERO, «Menor de edad y capacidad de ejercicio: Reto del Derecho Familiar contemporáneo», Revista sobre la Infancia y la Adolescencia, no2, 2012, p. 26; RAVETLLAT BALLESTÉ, «¿Por qué 18 años? La mayoría de edad civil en el ordenamiento jurídico español, Anales de la Cátedra Francisco Suárez, n49, 2015, pp. 151 y ss.; SÁNCHEZ HERNÁNDEZ, El sistema de protección a la infancia y a la adolescencia Tirant Lo Blanch, 2017, pp. 25 y ss. 
desarrollo de la personalidad. Donde se verifique la competencia de autogobierno debe reconocerse inmediatamente y en esa misma medida, la aptitud para ejercitar de manera autónoma derechos y obligaciones ${ }^{3}$.

Una vez más el legislador catalán se adelanta al Derecho Común en acatar los postulados de la Convención de los Derechos del Niño de $1989^{4}$. Sin embargo, la ratificación por España, un año más tarde, de la citada Convención hizo tambalear la idea de que la minoría de edad se configura sin más como un estado civil que delimita un determinado ámbito de la capacidad de obrar

La idea que sustenta la Convención es la participación del menor en los asuntos que le competen, no como una finalidad en sí misma, si no como un procedimiento que garantice la capacidad del menor en la toma de decisiones en aquellos temas que a ellos les afecten. La Convención ofrece un panorama en el que la persona menor de edad es un individuo, además de miembro de una familia y de una comunidad, con derechos y responsabilidades adaptados a sus distintas etapas de desarrollo y crecimiento. Al aceptar los derechos de los menores desde esta perspectiva, la Convención orienta firmemente sus mandatos hacia el pleno reconocimiento de la personalidad integral del menor.

Sentadas estas bases por la Convención, vinculantes para España desde la ratificación del Convenio, podemos afirmar que el menor tiene una capacidad natural como presupuesto ineludible de su capacidad de obrar exigiéndosele un mínimo de madurez: la imprescindible para poder cuidar por sí mismo sus propios intereses, para gobernar su persona y bienes o simplemente para actuar con total libertad e independencia. La capacidad de obrar del menor ha de ir unida necesariamente al progreso de su raciocinio que, obviamente, no es igual en todas las etapas de la niñez ya que en su delimitación confluyen múltiples circunstancias y factores ${ }^{5}$.

El artículo 12.1 de la Convención de los Derechos del Niño determina que para delimitar el ámbito de la intervención autónoma de los menores de edad ha de tenerse en cuenta «tanto su edad como su madurez». Por lo tanto, el mero indicador cronológico no puede determinar la trascendencia, validez y efectos de los actos por ellos acometidos. Los niveles de comprensión de una persona no siempre van ligados de manera uniforme a su edad biológica. Por ello, la información, el nivel educativo, la experiencia, el entorno, las expectativas sociales y culturales y el grado de apoyo, contribuyen, más allá de la edad alcanzada por el menor, a la mayor o menor capacitación del niño para formarse un juicio racional e independiente ${ }^{6}$.

Por lo tanto, los menores deben dejar de ser contemplados desde un punto de vista teórico como sujetos y objetos pasivos de protección para ser considerados como individuos autónomos a los cuales se les debe reconocer, de acuerdo con su edad y su nivel de raciocinio, sujetos de derechos con aptitud suficiente para tomar ciertas decisiones.

3 RAVETLLAT BALLESTÉ, «La capacidad de obrar de la persona menor de edad no emancipada a la luz del Libro II del Código Civil de Cataluña (artículos 211-3 y 211-5)», InDret, Revista para el Análisis del Derecho, 2017, pp. 5-7.

4 B.O.E. $n^{\circ} 313$, de 31 de diciembre de 1990.

5 BARTOLOMÉ TUTOR, El reconocimiento de los menores de edad de capacidad de obrar progresiva en los actos relativos a los derechos de la personalidad con especial referencia al papel de los responsables parentales. Tesis Doctoral dirigida por LÁZARO GONZÁLEZ, Universidad Pontificia de Comillas, 2014.

6 RAVETLLAT BALLESTÉ, «La capacidad de obrar...cit., p. 9. 
Si bien nuestro CC no reconoce estos postulados de forma expresa como hace el CCCat..sí encontramos ciertos preceptos en su articulado en donde las sucesivas reformas legislativas acaecidas cumplen el mandato de la Convención. Y ello lo podemos afirmar tanto desde la vertiente patrimonial como extrapatrimonial de la actuación de un menor.

\section{EL DERECHO DE ASOCIACIÓN DEL MENOR DE EDAD}

En este sentido el art. 162 del CC al delimitar el binomio representación legal de menores y patria potestad establece como principio general que «los padres que ostenten la patria potestad tienen la representación legal de sus hijos menores no emancipados» para, a continuación, establecer una serie de salvedades que afectan tanto al orden de actuación patrimonial como extrapatrimonial del menor. Entre estas últimas exceptúa en su apartado primero de tal representación «los actos relativos a los derechos de la personalidad que el hijo, de acuerdo con su madurez, puede ejercitar por sí mismo». Negar la capacidad de obrar en el ámbito de los derechos de la personalidad cuando el menor reúne condiciones intelectuales, volitivas y cronológicas suficientes para ejercitarlos por sí mismo, puede constituir una vulneración del derecho a la dignidad y al libre desarrollo de la personalidad del individuo, reconocidos en el artículo 10 de la Constitución Española como valores superiores del ordenamiento jurídico.

Entre los derechos de la personalidad que el menor pudiera ejercitar por sí mismo cuando concurran las condiciones volitivas y cronológicas exigidas por la legislación que lo desarrolla se encuentra el derecho de asociación. La Constitución Española de 1978 en su Capítulo II, Sección 1 a , bajo la rúbrica «De los Derechos Fundamentales y Libertades Públicas» reconoce de forma genérica en su artículo 22 el derecho de asociación. Se trata de un derecho que se reconoce a todas las personas, sin limitar su titularidad a aquellos que sean mayores de edad. Sin embargo, aunque nada se diga en el precepto constitucional, es evidente que, como ocurre con todos los derechos fundamentales, no se trata de un derecho absoluto y su ejercicio ha de llevarse a cabo conforme a lo dispuesto en las leyes ${ }^{7}$.

Por su parte, en el artículo 15.1 de la Convención Naciones Unidas sobre los derechos del niño reconoce de forma explícita el derecho del niño a la libertad de asociación y a la libertad de celebrar reuniones pacíficas. La Convención no tiene las características técnicas de un texto de normativo de eficacia inmediata. Su articulado no es sino la formulación de una serie de principios que, precisamente por carecer de una redacción

7 Sobre el derecho de asociación como derecho fundamental cuya titularidad corresponda a menores, vid. ALÁEZ CORRAL, «El ejercicio autónomo de los derechos fundamentales por el menor de edad», Revista Europea de Derechos Fundamentales, n²1, 2013, pp. 47 y ss., CABALLERO LOZANO, «La capacidad asociativa del menor de edad» en Estudios Jurídicos en Homenaje al Profesor Luis Diez Picazo, coord. CABANILLAS SÁNCHEZ, Vol. I, 2002, pp. 310 y ss.; DÍAZ ALABRAT, «El derecho de asociación de los menores», RDP, septiembre, 2002, pp. 616 y ss.; HERNÁNDEZ DÍEZ, «Reflexiones jurídicas sobre el asociacionismo juvenil: A partir de la Tesis de REVERTE MARTÍNEZ: El derecho fundamental de asociación como instrumento de cambio social: las Asociaciones Juveniles, Cuadernos de Investigación de la Juventud, nº3, 2017, pp. 6 y ss; MORETON SANZ, «El ejercicio de los derechos de ciudadanía y de la personalidad por los menores de edad: análisis particular del reconocimiento de la situación de dependencia en España», Revista sobre Infancia y Adolescencia, $\mathrm{n}^{\circ} 1,2011$, pp. 59 y ss.; PÉREZ CONCHILLO, «Los derechos de la personalidad de los menores en internet», Diario La Ley, nº009; REVERTE MARTÍNEZ, «La regulación de las asociaciones juveniles en el ordenamiento jurídico español», Revista Jurídica de la Región de Murcia, nº52, 2018, pp. 84 y ss.; 
técnica necesaria, ineludiblemente ha de desarrollarse por el legislador nacional, para así cumplir con el compromiso del Estado Español al ratificarla.

Por lo tanto, el derecho de asociación es un derecho fundamental que contribuye al libre desarrollo y personalidad del menor y que, como derecho personalísimo que es, su ejercicio compete a su titular, pese a su minoría de edad, sin injerencias de sus representantes legales siempre y cuando concurran los requisitos de madurez y de edad exigidos por la legislación que lo desarrolla.

¿Por qué incidimos tanto en el derecho de asociación en relación con el papel que pueden desempeñar los menores en una cofradía o hermandad? La razón no es otra que la siguiente hipótesis que planteamos: La naturaleza jurídica de las hermandades y cofradías es una respuesta al libre ejercicio del derecho de asociación de los individuos que la fundan y posteriormente la integran. Si este derecho fundamental es reconocido a todo sujeto de derecho por el simple hecho de serlo, es razonable que nos planteemos la posible fundación de una hermandad o cofradía por menores de edad en quienes concurran capacidad volitiva e intelectiva así como la edad exigida por la normativa que desarrolla este derecho. No obstante, en esta labor debemos distinguir dos planos jurídicos: por un lado, el referido al derecho de asociación en el ámbito civil y por otro, el desarrollo y ejercicio de este derecho en el ámbito del Derecho Canónico ya que al fin y al cabo las cofradías y hermandades son asociaciones publicas de fieles. Sin embargo, nos parece oportuno el planteamiento de esta hipótesis en ambos órdenes jurídicos.

\subsection{El ejercicio del derecho de asociación por el menor en el ámbito civil}

Por lo que respecta al ámbito civil, tanto el artículo 15 de la Declaración de los Derechos del Niño como el artículo 22 de nuestra Constitución Española establecen un enunciado abstracto del derecho de asociación referido a los menores de edad. El derecho es desarrollado posteriormente por dos normativas con carácter de Ley Orgánica: por un lado por el artículo 7 de la Ley Orgánica 1/1996, de 15 de enero de Protección Jurídica del Menor ${ }^{8}$ y, por otro, por el artículo 3 de la Ley Orgánica 1/2002, de 22 de marzo reguladora del Derecho de Asociación".

El artículo 7 de la L.O. 1/1996 contempla el derecho de asociación si bien circunscrito únicamente a la condición de menor -asociaciones infantiles y juveniles-, diferenciándose por tanto del derecho de asociación que con carácter general desarrolla el segundo de los textos normativos referidos cuyo sujeto activo es el sujeto de derechos como condición inherente a la personalidad independientemente de la edad cronológica. En este sentido los menores tienen derecho a formar parte de asociaciones y organizaciones juveniles de partidos políticos y sindicatos de acuerdo con la ley y los estatutos y a promover asociaciones infantiles y juveniles e inscribirlas de conformidad con la ley. Los menores podrán formar parte de los órganos directivos de estas asociaciones. Por su parte, el artículo 2.1 de la L.O.1/2002 establece que «todas las personas tienen derecho a asociarse libremente para la consecución de fines lícitos». Evidentemente los menores de edad están incluidos en esta redacción, si bien en su caso ese derecho tiene características propias de ejercicio que se corresponden con la condición del menor como sujeto

8 B.O.E. $n^{\circ} 15$, de 17 de enero de 1996; en adelante L.O. 1/1996.

9 B.O.E. $n^{\circ} 73$, de 26 de marzo de 2002, en adelante L.O. 1/2002. 
protegido jurídicamente. Es por ello que el artículo 3 del citado texto normativo incluyó por primera vez en nuestro ordenamiento la regulación del derecho general de asociación de los menores. En concreto la normativa, tras exigir una única capacidad para constituir asociaciones y formar parte de las mismas -capacidad de obrar y no estar sujeto a ninguna condición legal para el ejercicio de este derecho-, establece en el apartado b) las peculiaridades del mismo cuando el derecho de asociación es ejercido por menores fuera del ámbito propio de las llamadas asociaciones infantiles y juveniles de cuya regulación se encarga la L.O. 1/1996. En este sentido, establece que podrán constituir asociaciones y formar parte de las mismas (...) «b) Los menores no emancipados de más de catorce años con el consentimiento, documentalmente acreditado, de las personas que deban suplir su capacidad, sin perjuicio del régimen previsto para las asociaciones infantiles, juveniles o de alumnos en el artículo 7.2 de la Ley Orgánica 1/1996, de 15 de enero, de Protección Jurídica del Menor».

Por lo tanto, hemos de distinguir:

- $\quad$ por un lado, la posibilidad de que menores de edad ejerciendo el derecho de asociación que les reconoce el artículo 7 de la L.O.1/1996 promuevan e inscriban asociaciones exclusivamente infantiles y juveniles como expresión de su derecho a participar plenamente en la vida social, cultural y artística.

- $\quad$ por otro lado, la posibilidad de que estos menores constituyan y formen parte de asociaciones como expresión del derecho general de asociación, no circunscrito a asociaciones infantiles y juveniles regulado en su caso por el artículo 3 de la L.O. 1/2002.

El ejercicio del derecho, bien sea al amparo de la L.O. 1/1996 como de la L.O.1/2002, requiere una edad mínima, los 14 años, si bien y siendo consecuente con el calificativo de infantil o juvenil que caracteriza a las primeras se establece como límite de edad para su pertenecía los 30 años. Por el contrario, cuando los menores optan por la constitución de la misma al amparo de la Ley Orgánica reguladora del derecho de asociación, no existe límite cronológico para formar parte de la misma, si bien sí para su constitución bajo los auspicios del artículo 3 ya que llegada la mayoría de edad el sujeto de derecho con plena capacidad de obrar escaparía del ámbito de aplicación del citado precepto pero no así de la norma.

Respecto a la capacidad exigida al menor para la constitución de una y otra se entiende que es la capacidad natural que debe ostentar un menor de 14 años. Se presume que el menor reúne condiciones intelectivas y volitivas suficientes para el ejercicio de este derecho de la personalidad, constatado un dato meramente objetivo como es el de la edad. El ejercicio de este derecho en relación con las asociaciones infantiles y juveniles comprende la posibilidad de promoverlas e inscribirlas de conformidad con la ley e incluso se permite al menor formar parte de sus órganos directivos Ahora bien, sí se aprecian divergencias en el ejercicio del derecho de asociación. En relación con las asociaciones infantiles y juveniles es necesario nombrar un representante legal con plena capacidad para que la asociación pueda obligarse civilmente, por ejemplo, para poder arrendar un local donde se fije la sede de la asociación. Por lo tanto, se entiende que pese a que el socio menor tiene capacidad natural suficiente para constituirla se le excluye para poder obligar civilmente a la asociación. Sin embargo, en el ámbito del ejercicio del derecho de 
asociación con carácter general, no circunscrito a las asociaciones infantiles y juveniles, el complemento de capacidad que se le exige al menor lo será incluso para la constitución misma de la asociación al establecer la norma que junto al consentimiento de los menores haya de prestarse «el de la persona que deba suplir su capacidad». No es afortunada la redacción de la ley en este precepto por cuanto se entiende que un menor de 14 años posee suficiente conocimiento natural, por lo que la expresión utilizada debería ser completar su capacidad pero no suplirla. Este complemento de capacidad, que se hace efectivo con el consentimiento, ha de proceder de quienes representen legalmente al menor. Serán sus padres o tutores quienes suplan la capacidad del menor en los actos no personalísimos para los que aquél carece de capacidad. Este consentimiento ha de estar «documentalmente acreditado», es decir, ha de ser expreso y revestir forma escrita, bien pública o privada ${ }^{10}$.

En conclusión, los menores mayores de 14 años pueden constituir asociaciones siendo el consentimiento de los mismos condición suficiente para constituirla siempre y cuando las mismas tengan carácter infantil o juvenil, si bien este consentimiento habrá de ser suplido por el de sus representantes legales cuando la creación de la misma sea consecuencia del ejercicio del derecho general de asociación. Si bien en las primeras el menor puede formar parte del gobierno de la misma, la L. O. 1/2002 les prohíbe expresamente formar parte de los órganos de representación de la asociación -artículo 11.1.2 $2^{\mathrm{a}}$, párrafo-. En las asociaciones infantiles y juveniles la intervención del menor bajo el complemento de capacidad del representante legal incluye la administración de los bienes sociales, la representación legal de la asociación frente a terceros así como la asunción de obligaciones contractuales que precisen plena capacidad de obrar. El órgano de gobierno en este tipo de asociaciones puede estar integrado únicamente por menores de edad en cuyo caso es necesario el nombramiento de un representante para el ejercicio de estas actuaciones o bien puede estar integrado por mayores y menores de edad, siendo nombrado el representante legal entre los socios mayores de edad. Por el contrario, cuando el nacimiento de la asociación es consecuencia del ejercicio del derecho de asociación por menores al amparo de lo dispuesto en el artículo 3 de la L.O. 1/2002, el nombramiento de un menor para un órgano de representación es un acto nulo de pleno derecho por aplicación de lo dispuesto en el artículo 6.3 del $\mathrm{CC}^{11}$. No obstante, no establece la ley objeción alguna para la posible pertenencia del menor a los órganos de gobierno de la asociación que no sean de representación como puede ser la Asamblea General de Socios.

Un estudio comparado del ejercicio del derecho de asociación por menores de edad en los textos normativos trabajados nos lleva a la siguiente conclusión:

El menor de edad puede ejercitar por sí mismo este derecho al amparo de lo dispuesto en el art. 162 del CC pues se entiende que goza de capacidad natural para ello cuando concurran los siguientes requisitos:

a. el haber alcanzado los 14 años como criterio cronológico objetivo de atribución que habilita al menor para actuar de manera autónoma.

b. la naturaleza personalísima del derecho de asociación como derecho fundamental que contribuye al desarrollo integral de la personalidad del menor.

10 DÍAZ ALABART, Art. Cit., pp. 635-636.

11 Ibidem. 
c. el menor ha de ser consciente de los efectos derivados de su decisión de ejercitar este derecho siempre y cuando redunde en su beneficio o interés. La exigencia del representante legal que supla la capacidad del menor bien para obligarse respecto a terceros -asociaciones infantiles y juveniles- o incluso para constituir la misma cuando ejercita el derecho de asociación en su vertiente general no es más que un mecanismo de protección jurídica que el ordenamiento jurídico implanta como expresión del principio de protección del interés superior del menor que ha de impregnar cualquier actuación legislativa que afecte a menores.

Por lo tanto, según la legislación vigente en el ámbito civil no habría problema alguno para que los menores de edad pudiesen promover la fundación de una cofradía o hermandad al amparo de su legislación como expresión del ejercicio del derecho de asociación siempre y cuando cumpliesen lo preceptuado por las leyes orgánicas que regulan el mismo en relación con los menores. Sin embargo, si consultamos cualquiera de los estatutos de una cofradía o hermandad en nuestro territorio nacional estas se constituyen como asociación pública de fieles.

\subsection{El derecho de asociación del menor en el ámbito del derecho canónico. Espe-} cial referencia a la participación del menor en cofradías y hermandades

\subsubsection{El derecho de asociación del menor de edad en el ámbito propio del Derecho Canónico}

El Código de Derecho Canónico reconoce el derecho de asociación en el canon 215 al proclamar que «los fieles tiene la facultad de fundar y dirigir libremente asociaciones para fines de caridad o piedad o para fomentar la vocación cristiana en el mundo». San Juan Pablo II en la Exhortación Apostólica Christifideles Laici reconoce que esta facultad no es una concesión de la autoridad, sino que se deriva del Bautismo, en cuanto sacramento que llama a todos los fieles laicos a participar activamente en la comunión y misión de la Iglesia. Puede considerarse como un derecho fundamental de todos los miembros del pueblo de Dios ${ }^{12}$.

En aras al ejercicio de este derecho el canon 298 del Código de Derecho Canónico establece que «Existen en la Iglesia asociaciones distintas de los institutos de vida consagrada y de las sociedades de vida apostólica, en las que los fieles, clérigos o laicos, o clérigos junto a laicos, trabajan unidos, buscan fomentar una vida más perfecta, promover el culto público o la doctrina cristiana o realizar otras actividades de apostolado, a saber, iniciativas para la evangelización, el ejercicio de obras de piedad o de caridad, y la animación con espíritu cristiano del orden temporal».

La fundación de una hermandad o cofradía responde al ejercicio del derecho de asociación en el ámbito del Derecho Canónico. Si consultáramos los Estatutos de cualquiera de las hermandades y cofradías de nuestro territorio nacional, independiente de la Comunidad Autónoma donde nos ubicáramos, en todas ellas se repite la misma naturale-

12 MARTÍNEZ SISTACH, «Las Asociaciones de Fieles en la vida de la Iglesia» en Las Asociaciones de Fieles. Aspectos canónicos y civiles, Actas del VIII Simposio INTERNACIONAL DEL Instituto Martín de Azpilcueta. (Pamplona, 4-6 noviembre de 2009), Eunsa, Pamplona, 2009, p. 41. 
za: asociación pública de fieles nacidas como consecuencia del ejercicio del derecho de asociación.

Baste citar como ejemplo dos Hermandades icónicas en nuestro territorio andaluz. Así, la Pontificia y Real Archicofradía del Dulce Nombre de Jesús Nazareno del Paso y María Santísima de la Esperanza (Málaga) o la Pontificia y Real Hermandad y Cofradía de Nazarenos de Nuestro Padre Jesús del Gran Poder y María Santísima del Mayor Dolor y Traspaso (Sevilla). En la Regla Primera de los Estatutos de la mencionada en primer lugar la define como «asociación pública de fieles erigida canónicamente en Málaga antes de 1567 y puesta bajo el amparo pontificio por la bula Inhuman Nobis de Pio IV». Por su parte, la Regla Primera del Título Primero de los Estatutos del Gran Poder establece que «esta Asociación de fieles se denomina Pontificia y Real Hermandad y Cofradía de Nazarenos de Nuestro Padre Jesús del Gran Poder y Marías Santísima del Mayor Dolor y Traspaso».

La finalidad de las asociaciones públicas de fieles han de tener los fines que especifica el canon 215, fines que han de estar en la línea de la misión de la Iglesia en el mundo, que sean congruentes con ella y que colaboren directamente en su consecución. Estas finalidades rigen en torno a tres ejes:

- Culto: todo lo referente a la relación con Dios -oración, sacramento, liturgia, formación.

- Apostolado: predicación del mensaje cristiano -tanto para los miembros de la comunidad cristiana como para los que no pertenecen a ella-, catequesis, formación doctrinal y teológica de los fieles, ayuda para que lleven una vida cristiana más perfecta.

- Caridad: compartir el amor de Dios que ha sido derramado en los corazones de los fieles, especialmente de los más necesitados.

No obstante, este derecho de asociación no es un derecho absoluto e ilimitado pues en su ejercicio «los fieles han de tener en cuenta el bien común de la Iglesia, así como también los derechos ajenos y sus deberes respecto a otros -canon 223\&1- siendo competencia de la autoridad eclesiástica regular, en atención al bien común, el ejercicio de los derechos propios de los fieles. En este sentido y por lo que a las asociaciones públicas de fieles se refiere el canon $302 \& 1$ establece que «corresponde exclusivamente a la autoridad eclesiástica competente erigir asociaciones de fieles».

La causa eficiente de dichas asociaciones es el acto de jerarquía que las erige y que corresponde únicamente a ella, fundamentalmente por las finalidades propias y exclusivas de tales asociaciones que inciden en el bien público de la Iglesia. Sin embargo, ello no significa que la iniciativa de constituir estas asociaciones sea solo de la jerarquía. Sus fundadores pueden ser, y normalmente son, los restantes fieles, si bien únicamente adquirirán la naturaleza de asociaciones públicas cuando hayan sido erigidas por la autoridad eclesiástica competente. La función de la jerarquía eclesiástica respecto al derecho de asociación de los laicos plasmado en la constitución de una asociación pública de fieles será reconocerlo, tutelarlo, garantizar su ejercicio y promoverlo.

En el momento de constitución de una asociación de fieles esta intervención consiste en constatar si la asociación que se pretende crear opera dentro de los límites legíti- 
mos del derecho de asociación: tiene unos fines coherentes con la misión de la Iglesia y hay suficientes garantías de que va a actuar en comunión eclesial.

Así pues, en virtud de lo indicado por los cánones anteriormente expuestos se define una cofradía o hermandad como «aquellas asociaciones públicas de fieles católicos que reúnen a los creyentes en torno a la advocación de Cristo, de la Virgen o de un santo y promueven el culto público a los misterios de la fe, especialmente los referidos a la Pasión, Muerte y Resurrección del Señor, auspiciadas con fines piadosos, religiosos o asistenciales, establecidas conforme a los cánones del Título V del Código de Derecho Canónico ${ }^{13} \gg$.

El ámbito jurídico que corresponde a las hermandades y cofradías es el ordenamiento jurídico canónico, es decir, el Código de Derecho Canónico así como las normas episcopales del lugar -provincia- donde la asociación pública de fieles pretenda erigirse. Excede de nuestro trabajo el estudio de esta normativa particular propia de cada uno de las diócesis que conforman nuestro Estado. Por ello, y dado que todas ellas siguen unas pautas comunes, utilizaremos como eje de nuestro estudio las proporcionadas por la Diócesis de Málaga en el Decreto del Sr. Obispo sobre grupos parroquiales, hermandades y cofradías de 21 de abril de $2019^{14}$.

El artículo 8 del mencionado Decreto establece que «la erección canónica de una Hermandad o Cofradía es competencia exclusiva del Obispo». Sin embargo, pese a que es expresión del derecho de asociación que tiene todo católico por el mero hecho de estar bautizado "solo una verdadera necesidad pastoral y la búsqueda de un bien espiritual para la comunidad cristiana hará posible la creación de una nueva Hermandad o Cofradía»-artículo 1 del Decreto malacitano- correspondiendo el juicio valorativo de las razones pastorales promovidas por los fieles en última instancia al Obispo, oído el Vicario General así como el Delegado Episcopal de Hermandades y Cofradías, previo los informes del Párroco y Arcipreste correspondiente-artículo 3 del Decreto-. Estos preceptos no hacen sino constatar las exigencias del Derecho Canónico en la medida que toda la jerarquía eclesiástica de la provincia correspondiente interviene en la aprobación de una Hermandad si bien en última instancia la decisión la adopta el Obispo en virtud de la prerrogativa que le da el cargo que ostenta.

Los iniciadores de una cofradía o hermandad han de cumplimentar una solicitud que incluya un listado nominal de los miembros que deseen integrarla, acompañando partida de bautismo y firma de cada uno de ellos así como fotocopia del carnet de identidad. En relación con la edad que han de tener los promotores de una nueva Hermandad o Cofradía el artículo 13 establece que «todos han de ser mayores de 18 años y haber recibido los sacramentos de iniciación cristiana».

Este dato nos está indicando que, a diferencia de lo que ocurre en el ámbito civil, el menor mayor de 14 años, pese a ser sujeto activo del derecho de asociación en el ámbito canónico, tiene vedado el acceso a la promoción de una hermandad. La capacidad natural que el ordenamiento jurídico civil les reconoce gracias al desarrollo volitivo e intelectivo alcanzados los 14 años, resulta irrelevante a efectos de promocionar una nueva cofradía.

13 PÉREZ RUIZ, ponencia. IX Encuentro Provincial Pasión Ilicitana. http://www.pasionilicitana.com/ ENCUENTRO\%20PROVINCIAL/xixencuentro/PONENCIA\%20jose\%20perez\%20ruiz.pdf

14 https://www.dropbox.com/s/tbx8hj4204lt9on/00\%20Decreto\%2021\%20de\%20Abril.pdf?dl=0 
No obstante, llegados a este punto me gustaría traer a colación la refundación de una Hermandad sevillana por unos menores edad, todos ellos en torno a los 14 años, en los años noventa del siglo pasado.

En la Parroquia del Sagrario de la ciudad de Sevilla se veneraba el culto al Santísimo Cristo de la Corona. Este Cristo, de talla anónima fechada a principios del siglo XVI, fue titular de una Hermandad cuyos primeros datos escritos conocidos datan de 1632. Ortiz de Zúñiga en sus Anales Eclesiásticos de 1677 afirmaba que la Hermandad del Cristo de la Corona gozaba de gran devoción popular. Pertenecieron a ella ilustres personajes como los escultores Pedro Roldán y José Montes de Oca, el pintor Matías de Arteaga y Alfaro, numerosos canónigos de la Catedral sevillana, el Marqués de Parada o los Condes de Cantillana. Su Majestad. Se ha de destacar la relación con la Hermandad de Jesús Nazareno (El Silencio, considerada la madre y maestra de las Hermandades de Sevilla) que ofreció a la Hermandad de la Corona que sus hermanos, por el mero hecho de serlo, fueran admitidos en dicha Hermandad de forma automática sin el pago de su entrada correspondiente con el fin de favorecer la concordia entre ambas Hermandades. A principios del siglo XIX, comienza el declive de la Hermandad. Se ha podido constatar que en 1806 se venden todas las pertenencias de plata para sufragar los gastos del nuevo altar de su actual capilla en el ala izquierda de la Parroquia del Sagrario de Sevilla. La última referencia escrita de la antigua Hermandad es de un Acuerdo de Cabildo de 1860.

El inicio de la refundación de la actual Hermandad tiene lugar con la llegada de D. José Gutiérrez Mora como párroco del Sagrario de la Catedral sevillana en 1989. Con el fin de revitalizar su parroquia, dado que la mayor parte de su feligresía eran personas de avanzada edad, entusiasma a un grupo de jóvenes con la idea de esta refundación promoviendo los valores de culto, apostolado y caridad que caracteriza a la Hermandad. Así en 1991 un grupo de 50 jóvenes todos ellos entorno a los 14 años de edad firman simbólicamente un compromiso para reiniciar el culto al Santísimo Titular. Se inician a partir de entonces unos Vía-Crucis los Viernes de Dolores por los aledaños del entorno incomparable de la Catedral sevillana. Tal fue el entusiasmo de estos jóvenes que no dudaron en participar en un concurso en Canal Sur Televisión para recaudar los fondos necesarios con los que poder restaurar la imagen deteriorada del Titular que resistió los embates de diversos conflictos bélicos acaecidos en nuestro país, como por ejemplo, la ocupación francesa en la Guerra de la Independencia. En esta ocasión para ocultar la valía de la talla no se dudó en cubrir el rico estofado de la túnica tallada con pintura negra.

En 1991 comienza a gestarse la Asociación Parroquial del Santísimo Cristo de la Corona y Nuestra Señora del Rosario que fue aprobada por el Arzobispado en 1994 y posteriormente erigida como Hermandad de Penitencia en el año 2000. Es menester destacar que curiosamente en la fecha de aprobación de la Asociación Parroquial la mayoría de estos jóvenes refundadores ya habían alcanzado la mayoría de edad.

La actuación de estos jóvenes sorprendió tanto en la Sevilla de los 90 que transmitieron su entusiasmo no solo a las generaciones futuras, muchos de los hermanos actuales son hijos de aquellos jóvenes refundadores, sino incluso a los progenitores de los mismos que se involucraron en la puesta en marcha de la Hermandad. Valga como ejemplo que la talla del Cristo fue restaurada en los talleres de Dubé de Luque ya que su hijo Antonio Dubé Berdugo, escultor también como su padre, fue y sigue siendo hermano de la misma 
o el del primer joven refundador que pudo ser Hermano Mayor al cumplir los 18 años cuyo padre fue capataz del paso.

Este ejemplo me ha servido para mostrar que, si bien el ejercicio del derecho de asociación por menores mayores de 14 años les está vedado por el Derecho Canónico para la fundación de una hermandad, sí es posible involucrar y transmitir el entusiasmo en los menores de edad fomentando su participación activa en grupos o asociaciones parroquiales en las que pueden integrarse. Jurídicamente estos grupos y asociaciones parroquiales, antesala de una cofradía, únicamente podrán organizarse por personas mayores de edad, bautizados y en comunión con la Iglesia. Sin embargo, la participación de menores en los mismos desde la infancia y adolescencia les permitirá un crecimiento dentro de la labor evangelizadora que caracteriza a una hermandad y de la que formarán parte al llegar a la mayoría de edad en algunos casos participando como miembro activo en las labores de gestión y representación o bien como anónimo hermano.

\subsubsection{Especial referencia a la participación del menor de edad en Cofradías y Her- mandades: su inscripción y participación en la Estación de Penitencia}

Superado el proceso de iniciación en el que los promotores de la hermandad ya constituidos como Grupo Parroquial, cursan un periodo de formación cristina y cofrade bajo la responsabilidad del párroco encargado de su seguimiento, se procede a la redacción de los Estatutos de la Hermandad, según el modelo que recoge nuestro Decreto Diocesano de 21 de abril de 2019. En este momento los promotores de la hermandad podrán solicitar la aprobación de sus Estatutos así como solicitar la constitución canónica de la misma.

Los Estatutos cumplen la función de ser la norma básica de la asociación. En ella, los cofrades, de acuerdo con la legislación básica vigente, regulan todos los aspectos jurídicos internos (económicos o disciplinarios) como externos (relación con otras entidades) de la asociación y de sus asociados (derechos y obligaciones). Por ello, y por su gran importancia, estos estatutos son elaborados por la propia hermandad y, una vez aprobados por la Asamblea General, se presentarán para la aprobación por el Obispo diocesano.

Respecto al contenido del Estatuto me remito al modelo propuesto por el Decreto malacitano si bien, en relación con la materia tratada, es menester referirse a quiénes son los sujetos que pueden adquirir la condición jurídica de miembro de una cofradía o hermandad: cualquier fiel cristiano, sin distinción de sexo, no legítimamente impedido por el Derecho. También lo podrán ser las personas jurídicas, instituciones y administraciones públicas, siempre que no muestren una posición de rechazo a la Iglesia o a la fe y moral católica. Para la admisión de los hermanos será necesario dirigir una solicitud a la Junta de Gobierno, acompañada de su partida de bautismo y ser presentado por un hermano que tenga al menos dos años de antigüedad. Los menores de edad pueden ser inscritos como hermanos una vez bautizados, y desde su inscripción participarán en las gracias y beneficios espirituales concedidos a la cofradía o hermandad. La plenitud de los derechos los adquirirá con la mayoría de edad.

La mayor parte de las hermandades y cofradías cuentan con un arraigo social, cultural y familiar por lo que son muchos los hermanos inscritos por sus propios progenitores durante su minoría de edad una vez recibidas las aguas bautismales. En estos casos la 
solicitud de ingreso ha de ser presentada con la ratificación de los padres o representantes legales del menor.

La Estación de Penitencia es sin duda el culto más importante de cualquier hermandad o cofradía. Supone la manifestación pública de la Fe a Jesucristo y a alguna de las advocaciones a la Santísima Virgen en la que los menores de edad participan como nazarenos o monaguillos. Los sucesos acontecidos durante las últimas Madrugadas del Jueves Santo sevillano han promovido que distintas hermandades y cofradías de toda España reparen en una tutela especial a sus hermanos más vulnerables: los menores de edad. Sin duda, la participación de estos menores en el cortejo procesional supone una gran responsabilidad para la Junta de Gobierno que ha de hacerse cargo de los mismos durante las horas que participan en el recorrido por lo que son muchas las hermandades y cofradías que apuestan por mecanismos protectores adecuados para supervisar hasta el más mínimo detalle todo lo relacionado con la atención del menor.

Así, por ejemplo, en la Semana Santa sevillana, las hermandades de Pasión y el Gran Poder requieren que los padres o tutores del menor den su consentimiento por escrito para la realización de la estación de penitencia en su condición de nazareno, acólito o monaguillo. El modelo utilizado por la Hermandad de Pasión, exime de responsabilidad a la misma ante cualquier problema que pueda surgir al establecer que los progenitores o representantes legales «renuncian expresamente a reclamar a la Hermandad, así como a todos sus miembros, y les exime de cualquier tipo de responsabilidad derivada del suceso, dolencia, enfermedad, siniestro o percance que pudiera sufrir el hermano menor con motivo de su participación en la estación de penitencia» ${ }^{15}$. Por su parte, la Hermandad del Gran Poder se limita a pedir el consentimiento para realizar la estación de penitencia sin incluir ninguna cláusula que exima a la Hermandad de responsabilidad en el caso de siniestros o percances ${ }^{16}$. No obstante, la Corporación cuenta con un seguro de responsabilidad civil que da cobertura a la estación de penitencia. Gracias al mismo, el Consorcio de Compensación de Seguros se hizo cargo de los daños materiales causados por las avalanchas de 2017.

Algunos expertos cofrades ponen en entredicho la necesidad del preceptivo consentimiento escrito de los padres y tutores del menor para su participación en el cortejo procesional. Argumentan, entre otras razones, el artículo 7 de la L.O. 1/1996, o el artículo 3 de la L. O. 1/2002, textos normativos que de forma conjunta reconocen el derecho de participación, reunión y asociación de menores, uno limitado al ejercicio del mismo en las asociaciones infantiles y juveniles y el otro, enfocado desde el ejercicio del derecho de asociación con carácter general no limitado a las asociaciones de tales características siempre y cuando el menor sea mayor de 14 años y tenga un desarrollo volitivo e intelectivo adecuado a su edad. Corrobora en este sentido el artículo 162 del CC que asevera el derecho/deber de la patria potestad de los padres frente a los hijos exceptuando los actos relativos a los derechos de la personalidad, entre los que se encuentra la libertad religiosa.

Otro de los argumentos esgrimidos en esta línea lo manifestó el Magistrado sevillano y ex Hermano Mayor de la Vera Cruz, Bejarano Andrade en la mesa redonda organizada por el Consejo de Cofradías sevillano el 24 de febrero de $2019^{17}$. Considera el

15 http://www.hermandaddepasion.org/

16 https://www.gran-poder.es/

17 http://www.hermandades-de-sevilla.org/2019/1419-numero-722-abril-2019 
aplicador del Derecho que «cuando se habla de obtener el consentimiento de los padres para que los menores participen en la estación de penitencia todo el mundo da por hecho que sí hace falta». Sin embargo, en su opinión no haría falta una autorización expresa ya que cuando el menor es inscrito en una Hermandad, contrae la obligación tácita de participar en los cultos, entre ellos, la salida procesional al que se le une el consentimiento expreso que supone el sacarle la papeleta de sitio. No obstante, no está demás la obligación de los representantes legales de prestar autorización ad hoc ya que cuando un menor sale en una procesión se pone en manos de la Hermandad produciéndose una cesión temporal de la custodia inmediata por lo que la corporación durante este periodo contrae determinadas responsabilidades. El autor se muestra partidario que junto a la expedición de las papeletas de sitio, las Hermandades soliciten autorización de los representantes legales debido al hondo calado que está teniendo la socialización del daño, es decir, la búsqueda de culpables, algo de lo que no están exentas las Cofradías y Hermandades. Pensemos, por ejemplo, en la quema de un capirote por un cirio o por un acólito que echa cera al reclamo del público, generalmente menores de edad, que se retan a ver cuál de ellos alcanza a obtener la bola de cera más grande.

Por su parte, la Hermandad de la Macarena también se muestra especialmente sensible con sus hermanos menores ${ }^{18}$. En el año 2018 la Cofradía empezó a contar con un tramo especial para sus nazarenos menores de 15 años. Este tramo se sitúa en el cortejo del Señor de la Sentencia, tras los penitentes con especiales medidas. Además de disponer un lugar acotado en la salida y entrada de la Cofradía, cuenta con un mayor número de diputados que tienen formación sanitaria y amplia experiencia en el acompañamiento de los niños durante la estación de penitencia. El tramo va acompañado por hermanos de paisano y personal de seguridad. También se permite que los menores de edad lleven un acompañante.

En Málaga, la Cofradía del Santísimo Cristo de la Agonía y María Santísima de las Penas ha editado unas normas destinadas a los hermanos infantiles de estricto cumplimiento para estos así como para sus progenitores o representantes legales ${ }^{19}$. Con ello no solo se autoriza por los representantes legales del menor la salida procesional del mismo sino que también se evita una posible extracción del menor durante el cortejo. Tras sugerir un almuerzo liviano en el Martes Santos para evitar malestar en los niños durante la Estación Penitencial, regula de forma escrupulosa la vestimenta así como especifica el debido comportamiento del menor que viste la túnica por las calles de la ciudad antes del inicio del cortejo procesional. Convoca a todos ellos provistos de su papeleta de sitio y de su tarjeta de intercambio. Ningún familiar o allegado habrá de tener acceso al recinto. Tan solo sus representantes legales los llevarán a su sección correspondiente, ayudándoles a vestirse - en caso de que no lo hayan hecho previamente- y a ocupar su sitio. No podrán incorporarse a la procesión los que lleguen de manera tardía.

La tarjeta de intercambio se entrega a los progenitores o representantes legales para el momento de retirar al hermano infantil de la procesión. El funcionamiento es simple. El familiar que retira al niño debe entregar la tarjeta al responsable (mayordomo o comisión externa). Si el niño se reincorpora pedirá a los responsables la tarjeta de inter-

18 https://www.hermandaddelamacarena.es/

19 http://www.cofradiadelaspenas.org/ 
cambio a fin de retirar al infantil en un momento posterior. Se pretende con ello aumentar la seguridad de los menores de manera que solo a los poseedores de dicha tarjeta podrán los hermanos responsables de los menores en el cortejo entregar al hermano infantil.

Los hermanos infantiles que terminen la Estación de Penitencia saldrán por la puerta del Museo de la Hermandad a requerimiento del familiar portador de la tarjeta de intercambio una vez haya entrado la Santísima Virgen.

Otro aspecto participativo del menor en las Cofradías y Hermandades lo es por medio de las llamadas «Cofradías Infantiles y Juveniles» surgidas en el seno de cofradías y hermandades legalmente constituidas. Los integrantes de las mismas son menores de edad, hermanos de la cofradía por deseo de sus progenitores o por voluntad propia pese a lo cual han necesitado la aprobación y consentimiento de su representante legal. Estos menores constituyen las «canteras» de la Hermandad. Desde pequeños se les educa en el sentido cofrade, en el sentimiento religioso creando un cúmulo de experiencias personales y nazarenas en cada estación de penitencia. Cabe destacar en este sentido los Encuentros de Tercios Infantiles de Cierza (Murcia) ${ }^{20}$. El último de estos se celebró el 20 de octubre de 2019 organizado por la Vocalía de Juventud de la Junta de Hermandades Pasionarias. Más de un centenar de niños y niñas entre 6 y 12 años disfrutaron de un día de convivencia y diversión. Finaliza la jornada con una pequeña estación penitencial por los alrededores del lugar donde dos imágenes son procesionadas interviniendo los menores de forma activa no solo en su condición de portadores bajo unas andas sino también en la colocación de las imágenes y en la ornamentación del paso.

Algo semejante se está llevando a cabo en muchos colegios religiosos en los que el Viernes de Dolores los alumnos procesionan sus Sagrados Titulares como colofón de la formación religiosa que han recibido durante la cuaresma.

\section{APLICACIÓN DEL REGLAMENTO EUROPEO 2016/679 DE PROTECCIÓN DE DATOS Y DE LA LEY ORGÁNICA 3/2018, DE 6 DICIEMBRE, DE PROTECCIÓN DE DATOS PERSONALES Y GARANTÍAS DE LOS DERECHOS DIGITALES EN LAS HERMANDADES Y COFRADÍAS: SU REPERCUSIÓN EN LOS MENORES DE EDAD.}

La Ley Orgánica 3/2018, de 6 de diciembre, de Protección de Datos Personales y Garantías de los Derechos Digitales ${ }^{21}$ tiene por objeto adaptar al ordenamiento jurídico español el Reglamento (UE) 2016/679 del Parlamento Europeo y del Consejo de 27 de abril de 2016 relativo a la protección de las personas físicas en lo que respeta al tratamiento de sus datos personales y a la libre circulación de estos datos. Por lo tanto, el derecho fundamental de las personas físicas a la protección de datos personales, amparado por el artículo 18.4 de la Constitución Española se ejercerá de acuerdo con lo establecido en el referido reglamento así como por las disposiciones de la L.O. 3/2018, de 6 de diciembre -artículo 1 de la L.O. 3/2018-.

$20 \mathrm{https} / /$ www.laopiniondemurcia.es/multimedia/fotos/cieza/2014-10-27-27176-encuentro-tercios-infantilessemana-santa-cieza-2014.html

21 B.O.E. $\mathrm{n}^{\circ}$ 294, de 6 de diciembre de 2018, en adelante L.O.3/2018. 
El artículo 9.1 del Reglamento 2016/679 recoge el tratamiento de categorías especiales de datos personales. En este sentido dispone que «quedan prohibidos el tratamiento de datos personales que revelen el origen étnico o racial, las opiniones políticas, las convicciones religiosas o filosóficas, o la afiliación sindical y el tratamiento de datos genéticos, datos biométricos dirigidos a identificar de manera unívoca a una persona fisica datos relativos a la saludo datos relativos a la vida sexual o a la orientación sexuales de una persona física». No obstante, el apartado 1 no será de aplicación cuando concurra una de las circunstancias siguientes:

«b) el tratamiento es efectuado, en el ámbito de sus actividades legítimas y con las debidas garantías, por una fundación, una asociación o cualquier otro organismo sin ánimo de lucro, cuya finalidad sea política, religiosa o sindical. Siempre que el tratamiento se refiera exclusivamente a los miembros actuales o antiguos de tales organismos o a personas que mantengan contactos regulares con ellos en relación con sus fines y siempre que los datos personales no se comuniquen fuera de ellos sin el consentimiento de sus interesados».

Esta regulación es perfectamente ajustable al uso de los datos en las labores propias de una hermandad o cofradía en sus actividades cotidianas lo que significa que el tratamiento de los datos de los hermanos de una cofradía estará permitido siempre que sean utilizados para los fines propios de la misma y que podrán ser cedidos siempre que cuenten con el consentimiento de los miembros de la corporación religiosa.

El Reglamento establece en su artículo 8.1 que la edad en la que los menores pueden prestar por sí mismos consentimiento para el tratamiento de sus datos de carácter personal en el ámbito de los servicios de la sociedad de la información, (por ejemplo, en las redes sociales) es de 16 años. Sin embargo, permite rebajar esta edad y que cada Estado Miembro establezca la suya propia, estableciendo un límite inferior de 13 años. La normativa vigente cifra en 14 años la edad requerida al menor de edad para prestar consentimiento al tratamiento de sus datos personales -artículo 7.1-. "se exceptúan los supuestos es los que la Ley exija la asistencia de los titulares de la patria potestad o tutela para la celebración del acto o negocio jurídico en cuyo contexto se recaba el consentimiento para el tratamiento».

Llegados a este punto creo que conviene distinguir entre el acto de solicitud de ingreso en una cofradía o hermandad de un menor que corresponde a sus padres o representantes legales, según los Estatutos propios de cada corporación sobre la base de las disposiciones del Derecho Canónico y otra cuestión distinta la edad a partir de la cual los menores que ya forman parte de la misma pueden consentir al tratamiento de sus datos de carácter personal ya que según establece la actual Ley de Orgánica será a partir de los 14 años. En tanto en cuanto los menores no lleguen a esta edad el consentimiento recabado para el tratamiento de los datos de carácter personal habrá de ser el de los padres o representantes legales.

En este sentido todos los miembros de la Hermandad habrán de firmar una autorización para el manejo y cesión de sus datos, como por ejemplo puede ser el censo en las elecciones a Junta de Gobierno o la lista de salida en una protestación de la Fe.

Por lo tanto, con la actual normativa un abuelo no podrá inscribir a un menor de 14 años en la cofradía familiar ya que deberá contar con la autorización de los padres o 
tutores no solo para la inscripción del menor sino también para la cesión de sus datos de carácter personal.

\section{RECAPITULACIÓN}

El derecho de asociación es un derecho fundamental cuya titularidad compete al sujeto de derecho. Se trata de un derecho cuyo ejercicio efectivo puede hacerse en dos órdenes jurídicos diferentes: bien en el ámbito civil o bien en el ámbito del Derecho Canónico. El estudio comparado de este derecho en ambas vertientes tiene su razón de ser en la naturaleza jurídica de las hermandades y cofradías como respuesta al libre ejercicio del derecho de asociación de los individuos que la fundan y posteriormente la integran.

Sujetos activos de las asociaciones públicas de fieles lo son los sujetos de derecho, adultos y menores, que acaten y cumplimenten los requisitos exigidos por los Estatutos de la hermandad o cofradía en la que ingresan.

Sin embargo, esta legitimación merma considerablemente cuando lo que se propone es la promoción de una asociación de estas características por menores de edad. La capacidad natural que el ordenamiento jurídico civil les reconoce gracias al desarrollo intelectivo y volitivo alcanzado a los 14 años, resulta irrelevante a efectos de promocionar una cofradía o hermandad.

Es más, esta ausencia de legitimación en el ámbito del Derecho Canónico se extiende incluso al sujeto de derecho que haya alcanzado la mayoría de edad en beneficio de la jerarquía eclesiástica en su función de garante del derecho de asociación de los laicos bajo cuya iniciativa surge el germen de las asociaciones públicas de fieles.

Esta situación contrasta con la regulación del derecho de asociación en el otro orden jurídico estudiado. Como derecho fundamental que es, su regulación compete a una ley orgánica, siendo dos normas de estas características las encargadas del desarrollo del mismo cuando su ejercicio compete a un menor, si bien el ámbito objetivo de actuación de cada una de ellas no es coincidente: una se limita exclusivamente a las asociaciones infantiles y juveniles y otra al desarrollo general del derecho de asociación que asiste al menor siempre y cuando alcance el nivel volitivo e intelectivo al que antes hacíamos referencia y que la propia norma cifra en 14 años.

Este panorama legislativo nos inclina hacia un desfase en el ejercicio de este derecho por menores de edad según el ámbito en el que nos ubiquemos. Sin embargo, considero que esta discordancia es concluyente respecto a la legitimación activa que ostenta el menor para erigir una asociación infantil, juvenil o para el ejercicio común del derecho de asociación, pero no alcanza a otras actividades propias de una asociación en activo. Me estoy refiriendo, por ejemplo, a su representación, judicial o extrajudicial o a los ámbitos económico, contable o representativo de cada una de ellas donde es necesario la presencia de sujetos mayores de edad con plena capacidad.

Esta circunstancia es compartida en el ámbito del Derecho Canónico. Si bien el derecho de asociación cuya titularidad corresponde a los laicos está mediatizado por la autoridad eclesiástica para la erección de una hermandad, la vida jurídica una vez constituida corresponde a los órganos representativos de la misma, integrados por sujetos mayores de edad bajo la fiscalización de la jerarquía eclesiástica. 
Por lo tanto, la situación jurídica del menor de edad queda muy mermada en lo referente al ejercicio del derecho de asociación para la constitución de una asociación pública de fieles, quedando su intervención limitada al ejercicio de derechos y cumplimiento de deberes inherentes a su condición de hermano.

\section{BIBLIOGRAFÍA.}

Aláez Corral, Benito. «El ejercicio autónomo de los derechos fundamentales por el menor de edad», Revista Europea de Derechos Fundamentales, n²1. 2013.

BArtolomé Tutor, ArÁNZAZU. El reconocimiento de los menores de edad de capacidad de obrar progresiva en los actos relativos a los derechos de la personalidad con especial referencia al papel de los responsables parentales. Tesis Doctoral dirigida por LÁZARO GONZÁLEZ, Universidad Pontificia de Comillas, 2014.

Caballero Lozano, José María. «La capacidad asociativa del menor de edad» en Estudios Jurídicos en Homenaje al Profesor Luis Díez Picazo, coord. CABANILLAS SÁNCHEZ, Vol. I, 2002.

Degano, José Alejandro. «La ficción jurídica de la Minoridad y la Subjetividad Infantil, Fundamentos en Humanidades. 2006.

Díaz Alabrat, Silvia. «El derecho de asociación de los menores», Revista de Derecho Privado, 2002.

HERnÁNDEZ DíEZ, ENRIQUE. «Reflexiones jurídicas sobre el asociacionismo juvenil: A partir de la Tesis de REVERTE MARTÍNEZ: El derecho fundamental de asociación como instrumento de cambio social: las Asociaciones Juveniles, Cuadernos de Investigación de la Juventud. 2017.

Martín Briceño, CARLOS. «La capacidad contractual del menor no emancipado tras la Ley 26/2015, de 28 de julio, de modificación del sistema de protección a la infancia y a la adolescencia», Actualidad Civil, n³, 2017.

Martínez Sistach, Lluis. «Las Asociaciones de Fieles en la vida de la Iglesia» en Las Asociaciones de Fieles. Aspectos canónicos y civiles, Actas del VIII Simposio Internacional del Martín de Azpilcueta. (Pamplona, 4-6 noviembre de 2009), Eunsa.2009.

Montejo Rivero, Jetzabel Mireya. Menor de edad y capacidad de ejercicio: Reto del Derecho Familiar contemporáneo», Revista sobre la Infancia y la Adolescencia, $\mathrm{n}^{\circ} 2,2012$.

Moreton SAnz, Fernanda. «El ejercicio de los derechos de ciudadanía y de la personalidad por los menores de edad: análisis particular del reconocimiento de la situación de dependencia en España», Revista sobre Infancia y Adolescencia, 2011.

PÉrez Conchillo, María. «Los derechos de la personalidad de los menores en internet», Diario La Ley, $\mathrm{n}^{\circ} 9009$.

Ravetllat Ballesté, IsaAc. «¿Por qué 18 años? La mayoría de edad civil en el ordenamiento jurídico español, Anales de la Cátedra Francisco Suárez, nº49, 2015.

«La capacidad de obrar de la persona menor de edad no emancipada a la luz del Libro II del Código Civil de Cataluña (artículos 211-3 y 211-5)», InDret, Revista para el Análisis del Derecho, 2017.

Reverte Martínez, Francisco Manuel. «La regulación de las asociaciones juveniles en el ordenamiento jurídico español», Revista Jurídica de la Región de Murcia, n552, 2018.

SÁNCHEZ HERNÁNDEZ, CARMEN. El sistema de protección a la infancia y a la adolescencia Tirant Lo Blanch, 2017. 